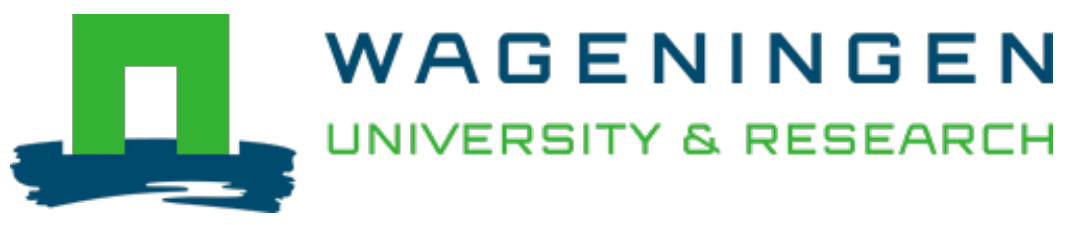

\author{
Rod-shaped polypeptide nanoparticles for siRNA delivery \\ International Journal of Biological Macromolecules \\ Li, Dan; Li, Xin; Bai, Jie; Liu, Ying; Vries, Renko et al \\ https://doi.org/10.1016/j.ijbiomac.2020.10.198
}

This article is made publicly available in the institutional repository of Wageningen University and Research, under the terms of article $25 \mathrm{fa}$ of the Dutch Copyright Act, also known as the Amendment Taverne. This has been done with explicit consent by the author.

Article $25 \mathrm{fa}$ states that the author of a short scientific work funded either wholly or partially by Dutch public funds is entitled to make that work publicly available for no consideration following a reasonable period of time after the work was first published, provided that clear reference is made to the source of the first publication of the work.

This publication is distributed under The Association of Universities in the Netherlands (VSNU) 'Article $25 \mathrm{fa}$ implementation' project. In this project research outputs of researchers employed by Dutch Universities that comply with the legal requirements of Article $25 \mathrm{fa}$ of the Dutch Copyright Act are distributed online and free of cost or other barriers in institutional repositories. Research outputs are distributed six months after their first online publication in the original published version and with proper attribution to the source of the original publication.

You are permitted to download and use the publication for personal purposes. All rights remain with the author(s) and / or copyright owner(s) of this work. Any use of the publication or parts of it other than authorised under article $25 \mathrm{fa}$ of the Dutch Copyright act is prohibited. Wageningen University \& Research and the author(s) of this publication shall not be held responsible or liable for any damages resulting from your (re)use of this publication.

For questions regarding the public availability of this article please contact openscience.library@wur.nl 


\title{
Rod-shaped polypeptide nanoparticles for siRNA delivery
}

\author{
Dan $\mathrm{Li}^{\mathrm{a}}$, Xin $\mathrm{Li}^{\mathrm{a}}{ }$, Jie Bai ${ }^{\mathrm{a}}$, Ying Liu ${ }^{\mathrm{a}}$, Renko de Vries ${ }^{\mathrm{b}, *}$, Yuan $\mathrm{Li}^{\mathrm{a}}{ }^{\text {a** }}$ \\ a Key Laboratory of Precision Nutrition and Food Quality, College of Food Science and Nutritional Engineering, China Agricultural University, 100083, China \\ ${ }^{\mathrm{b}}$ Laboratory of Physical Chemistry and Soft Matter, Wageningen University and Research, Stippeneng 4, 6708, WE, Wageningen, the Netherlands
}

\section{A R T I C L E I N F O}

\section{Article history:}

Received 21 June 2020

Received in revised form 21 October 2020

Accepted 24 October 2020

Available online $\mathrm{xxxx}$

\section{Keywords:}

siRNA delivery

Polypeptide

Nanoparticles

\begin{abstract}
A B S T R A C T
Rod-shaped nanoparticles have been reported to exhibit improved cellular uptake, intracellular processing and transport through tissues and organs, as compared to spherical nanoparticles. We use $C-S$-B triblock polypeptides composed of a collagen-like block $(C)$, a silk-like block $(S)$ and an oligolysine domain $(B)$ for one-dimensional coassembly with siRNA into rod-shaped nanoparticles. Here we investigate these siRNA encapsulating rod-shaped nanoparticles as a gene delivery system. Uptake experiments for $C-S-B$ and $C-S-B /$ siPlk1 particles indicate that these rod-shaped nanoparticles can efficiently deliver siPlk1 into HeLa cells. Moreover, $C-S-B /$ siPlk1 complexes display significant mPlk1 gene knockdown in a dose-dependent manner, causing apoptosis as intended. The lower effectiveness of $C-S-B /$ siPlk 1 in inducing cell death as compared to cationic lipid-based formulations is explained by the high lysosome- $C-S-B /$ siPlk1 co-localization ratio, which will need to be addressed in a future redesign of polypeptide sequence. Overall, the non-toxic and unique rod-shaped $C-S-B$ nanoparticles deserve further optimization as a new siRNA delivery system for cancer therapy.
\end{abstract}

(C) 2020 Published by Elsevier B.V.

\section{Introduction}

It has been established that not only nanoparticle (NP) size and surface chemistry dictate its fate when used as a drug delivery vehicle, but also the NP shape [1-3]. Whereas earlier work dealt with the impact of NP shape on cellular uptake and intracellular processing [4-8], more recently it has also been demonstrated that NP shape affects it transport through tissues and in organs [9-13].

Various nanoparticles, including inorganic nanoparticles and biopolymer nanoparticles, are designed with diverse strategies for delivering nucleic acids (such as DNA, pDNA, dsDNA, ssDNA, siRNA or miRNA) into living cells [14]. With respect to the delivery of small nucleic acids such as siRNA, the main nanoparticle delivery formulations currently in development are polymer and lipid nanoparticles [15,16]. Although both of them have advanced development over the last decade [17], it seems that the lipid formulations currently offering the best performance which is demonstrated by the recent introduction of the first FDA approved siRNA therapy approved for humans [18]. Meanwhile, other lipid-siRNA therapeutic agents are also in clinical trials. For example, TKM 080301, a siPlk1 based lipid agent which suppresses the expression of the tumor aggressiveness-related polo-like kinase I (Plk1), has already reach Phase II in clinical studies [19].

Both lipid- and polymer nanoparticles developed for siRNA delivery, however, are typically spherical [17]. The rod-shaped NP showed superior properties than spherical NP as a delivery system. For example, the

\footnotetext{
* Corresponding authors.

E-mail addresses: renko.devries@wur.nl (R. de Vries), yuanli@cau.edu.cn (Y. Li).
}

rod-shaped NPs possessed the highest permeability into the intestinal mucus barriers and cellular uptake into intestinal epithelium cells, which had the optimum bioavailability than spherical ones [20]. Indeed, the production of controlled size- and aspect ratio polymer or lipid nanoparticles as drug delivery vehicles is technologically complicated [21].

For the extreme limit of rod-shaped particles, however, one can resort to various types of one-dimensional self-assembly, for example by peptides or polypeptides. Indeed, we have previously designed a triblock polypeptide sequence composed of a collagen-like block $(C)$ for steric protection, a silk-like block $(S)$ for one-dimensional assembly into rod-shaped particles, and an oligolysine domain $(B)$ for binding to negative charged cargo [22]. When mixed with long single stranded DNA, double stranded DNA or mRNA, the C-S-B triblock polypeptide spontaneous co-assembles with the long nucleic acids to form rodshaped particles in which the nucleic acids are protected against nucleases [22,23]. As $C-S-B$ is composed of biological macromolecule, it is found that these particles are not toxic to HeLa cells and are nonhemolytic. However, a luciferase assay shows only a low mRNA transfection efficiency for HEK293 cells [23].

Given the high degree of control over the nanoparticle assembly when using genetically engineered polypeptides, and the fact that they allow for the assembly of very high aspect ratio nanoparticles, it is still interesting to explore whether the system may be more effective for other types of nucleic acids, such as siRNA. Indeed, both nanoparticle co-assembly and delivery may be very much affected by the type of encapsulated nucleic acid. For example, we have found that while for linear double stranded DNA, typically one DNA molecule is encapsulated 
in each nanoparticle, for mRNA, multiple chains are encapsulated in each nanoparticle $[22,23]$. Also, a more detailed study of the uptake of the rod-shaped particles by cells may elucidate bottle necks with respect to delivery that may be remedied by rationally improving the design of these polypeptide sequences.

More generally, as compared to well established and much investigated nanoparticles for nucleic acid delivery such as those based on lipids, synthetic polymers or natural virus-like particles, there is still much to learn for the more novel class of self-assembling nanoparticles based on proteins and polypeptides with de-novo designed amino-acid sequences. With this in mind, we here study particle formation of the $C$ $S$ - $B$ triblock polypeptides with Plk1 siRNA. We demonstrate a modest, dose-dependent gene knock-down effect for HeLa cells in vitro. We use fluorescence microscopy elucidate bottle-necks that will need to be addressed by modifying the sequence of the $C-S-B$ polypeptides to become efficient rod-shaped delivery vehicles for siRNA.

\section{Materials and methods}

\subsection{Materials}

Small interfering RNA targeting human polo-like kinases 1 (siPlk1) (sense strand, 5'-GAAGAAGAUCACCCUCCUUAdTdT-3'; antisense strand 5'-UAAGGAGGGUGAUCUUCUUCdTdT-3') and Cy5 decorated siPlk1-Cy5 are supplied by Guangzhou Ribo Life Science Co. Ltd. (Guangzhou, China). Fluorescence dye Cy3-SE is purchased from Fanbo Biochemical Co. (Beijing, China). DAPI that use to stain cell nucleus is obtained from Vector Laboratories (Burlingame, USA). Commercial gene transfection agent Lipofectamine RNAiMAX is purchased from Invitrogen (USA). Lyso Tracker probes are purchased from Cell Signaling Technology (USA). RNAse A (SL2072) and DNA marker (100-1500 bp, DM1011-50T) are both bought from Coollaber Science \& Technology Co. Ltd. (Beijing, China).

\subsection{Preparation and characterization of C-S-B/siPlk1 nanoparticles}

The $C-S-B$ polypeptide is produced and purified as reported previously, SDS-PAGE and MALDI-TOF results for the purified polypeptide are the same as obtained earlier, confirming that the material is of similar purity [22]. To prepare the $C-S-B$ nanorods, $1.1 \mathrm{mg} C-S$ - $B$ polypeptide is dissolved in $0.55 \mathrm{ml}$ phosphate buffer $(10 \mathrm{mM}, \mathrm{pH} 7.4)$. Then the solution is heated in a water bath at $65{ }^{\circ} \mathrm{C}$ for $1 \mathrm{~h}$. After cooled to room temperature, the nanorods are diluted into $1 \mathrm{mg} / \mathrm{ml}$ by above PBS buffer. For the gel retardation experiments, $C-S-B /$ siPlk1 samples are prepared by mixing constant volume of $3 \mathrm{mg} / \mathrm{ml}$ siPlk1 ( $1.67 \mu \mathrm{l}$ dissolved in RNase free water) with varying volumes $(2.86,5.72,11.4$, 28.7, 45.8 and $57.2 \mu \mathrm{l}$ ) of $1 \mathrm{mg} / \mathrm{ml} \mathrm{C-S-B}$ nanorods (dispersed in $10 \mathrm{mM}$, pH 7.4 phosphate buffer), followed by vortexing for $2 \mathrm{~min}$. The siPlk1 is constant at $500 \mathrm{ng}$, and the N/P (charge) ratios of the samples are $0,0.5,1,2,5,8$ and 10 . Samples are incubated at room temperature for $0.5 \mathrm{~h}$ before electrophoresis to let the interaction between siPlk1 and $C-S-B$ nanorods to proceed. The N/P ratio is the molar ratio of the total number of positively charged lysine residues $(\mathrm{N})$ on $C-S-B$ polypeptides to the total number of negatively charged phosphate groups (P) on siRNA molecules. Samples and free siPlk1 (500 ng) are electrophoresed in $1 \%$ agarose gels which stains with GelRed and visualized by a gel imaging system (Tanon 1600 ). To observe the gene protection of $C-S-B$ nanoparticles, $60 \mu \mathrm{l} C-S-B / \operatorname{siPlk} 1(\mathrm{~N} / \mathrm{P}=5,1 \mathrm{mg} / \mathrm{ml}$ with $1 \mu \mathrm{g}$ siPlk1) samples are added with 5, 10, 15 and $20 \mu \mathrm{g}$ RNAse A, respectively. Free siPlk1 (1 $\mu \mathrm{g})$ in $60 \mu \mathrm{l}$ RNAse free water which incubated with $5 \mu \mathrm{g}$ RNAse A is used as control. After incubation at room temperature for $10 \mathrm{~min}$, all samples are analyzed by electrophoresis as aforementioned.

The morphology of self-assembled $C-S-B$ particles, both before and after siPlk1 binding, is visualized by transmission electron microscope (TEM, JEM-1400, JEOL). Samples for TEM are prepared by placing $10 \mu \mathrm{l}$
$C-S-B$ and $C-S-B /$ siPlk1 on 200-mesh carbon copper grids and negatively staining with uranium acetate. $\zeta$-Potentials of self-assembled $C-S$ - $B$ particles $(1 \mathrm{mg} / \mathrm{ml})$, before and after siPlk1 binding are measured by electrophoretic light scattering (Nano-ZA 90, Malvern) at $25^{\circ} \mathrm{C}$ in both double-distilled water $\left(\mathrm{ddH}_{2} \mathrm{O}\right)$ and $\mathrm{PBS}$ buffer. Meanwhile, the size distribution of $C-S-B$ and $C-S-B /$ siPlk1 is estimated through electrophoretic light scattering (Nano-ZA 90, Malvern) as well. The measurement of $\zeta$ potentials and size-distribution of $C-S-B$ and $C-S-B /$ siPlk1 is operated in triplicate.

\subsection{Analysis of cellular uptake of C-S-B and C-S-B/siPlk1 nanoparticles by confocal laser scanning microscope and flow cytometry}

HeLa (human cervical cancer) cells are purchased from the Cell Resource Center (Peking Union Medical College headquarters of National Infrastructure of Cell Line Resource, NSTT). Cells are cultured in Dulbecco's Modified Eagle's medium (DMEM) (Gibco) supplemented with $10 \%$ fetal calf serum (Gibco) and $1 \%$ penicillin/streptomycin (Gibco) at $37{ }^{\circ} \mathrm{C}, 5 \% \mathrm{CO}_{2}$.

To visualize the cellular uptake of the nanorods, $C-S-B$ nanorods are covalently labeled with $\mathrm{Cy} 3$ dye. $\mathrm{Cy} 3-\mathrm{SE}$ fluorescent dye with activated ester group can covalently attach to the amino groups in C-S-B polypeptides by mixing $5 \mu \mathrm{l}$ Cy3-SE $(1 \mathrm{mg} / \mathrm{ml}$ ) with $3 \mathrm{ml}$ freshly prepared $C-S-B$ nanorods $(1 \mathrm{mg} / \mathrm{ml})$ in $10 \mathrm{mM}$, pH 7.4 phosphate buffer. The mixture is incubated at room temperature for $2 \mathrm{~h}$ and the unreacted dye is removed by dialysis in water for $8 \mathrm{~h}$. To evaluate the siPlk1 transfection efficiency of $C-S-B$ nanorods, $C-S-B /$ siPlk1-Cy5 $(\mathrm{N} / \mathrm{P}$ ration $=5$ ) nanorods are prepared by binding siPlk1-Cy5 to $C-S-B$ nanorods directly.

The cellular uptake of the $C-S-B$ and the $C-S-B /$ siPlk1 nanoparticles are observed by confocal laser scanning microscopy. HeLa cells are seeded in coverglass-bottom plates at a density of $1 \times 10^{5}$ cells/dish. After growing in standard culture conditions for $24 \mathrm{~h}$, Cy3-labeled $C-S$ $B$ nanoparticles ( $C-S-B / C y 3)$, or $C-S-B /$ siPlk1 nanoparticles with Cy5 labeled siRNA ( $C-S-B /$ siPlk1/Cy5) are added to the culture medium and the final concentration corresponding to $100 \mu \mathrm{g} / \mathrm{ml}$ of $C-S-B$. The N/P ratio for the $C-S-B / \operatorname{siPlk} 1 / C y 5$ nanoparticles is 5 , which corresponds to a siRNA concentration of $1.67 \mu \mathrm{g} / \mathrm{ml}$. After incubation for $4 \mathrm{~h}$, cells are rinsed with PBS for 3 times and fixed with $4 \%$ paraformaldehyde for $15 \mathrm{~min}$. The cell nucleus is stained with one drop solution contained anti-fade fluorescence mounting medium and DAPI. Cells are observed using CLSM (A1, Nikon) with the excitation channel of $405 \mathrm{~nm}$ for DAPI, $561 \mathrm{~nm}$ for $\mathrm{Cy} 3$ and $654 \mathrm{~nm}$ for Cy5.

The cellular uptake of $C-S-B$ and $C-S-B /$ siPlk1 nanoparticles is further evaluated by flow cytometry. HeLa cells are seeded in 6 -well plates at a density of $25 \times 10^{4}$ cell/well and incubated overnight for further adherence. $C-S-B / C y 3$ or $C-S-B / \operatorname{siPlk} 1 / C y 5$ nanoparticles are incubated with the cells for $4 \mathrm{~h}$. The final concentration of nanoparticles is corresponded to $100 \mu \mathrm{g} / \mathrm{ml}$ of $C-S$ - $B$. For the siRNA containing nanoparticles, the siRNA concentration is $1.67 \mu \mathrm{g} / \mathrm{ml}$, corresponding to an $\mathrm{N} / \mathrm{P}$ ratio of 5:1. After rinsing by PBS and digestion by trypsin, cells are collected and evaluated by flow cytometry (FC500, Beckman) using the $\mathrm{PE}$ channel to detect the $\mathrm{Cy} 3$ fluorescent signals of $C-S-B / C y 3$ and the APC channel to detect the Cy5 fluorescent signals of $C-S-B /$ siPlk1/Cy5.

2.4. Analysis of gene knockdown effect of siPlk1 loaded C-S-B nanoparticles by reverse transcription polymerase chain reaction ( $R T-P C R$ )

HeLa cells at a density of $25 \times 10^{4}$ cells/well are seeded in a 6-well plate. Cells are cultured at standard conditions until 70-80\% confluency before gene transfection. The commercial gene transfection agent Lipofectamine RNAiMAX is used as a positive control which follow the manufacturer's protocol. $3 \mu \mathrm{g}$ siPlk1 and $9 \mu \mathrm{l}$ Lipofectamine RNAiMAX reagent are diluted to $150 \mu$ DMEM medium, respectively. Mix the two reagents and incubate for $5 \mathrm{~min}$ at room temperature. After that, the siPlk1-lipid complex with another $700 \mu \mathrm{l}$ DMEM medium are transferred to cells for $48 \mathrm{~h}$. Free siPlk1 incubated with the cells at a 
concentration of $7 \mu \mathrm{g} / \mathrm{ml}$ for $48 \mathrm{~h}$ is used as another control. C-S-B/siPlk1 nanoparticles formulated at an N/P ratio of 5:1 are incubated with the cells at siRNA concentrations of 1,4 and $7 \mu \mathrm{g} / \mathrm{ml}$ for $48 \mathrm{~h}$. Total RNA of each group is isolated by Trizol reagent and quantified using a Nanodrop One spectrophotometer (Thermo Scientific, USA). The reverse transcription process is carried out using the PrimeScript 1st strand cDNA Synthesis Kit (Takara). The RT-PCR is carried out by a StepOnePlus Real-time PCR system (Applied Biosystems) with the forward and reverse primers (Plk1: forward 5'-AGCCTGAGGCCCGATACTACCTAC-3'; reverse: 5'-ATTAGGAGTCCCACACAGGGTCTTC-3'. GAPDH: forward 5'TTCACCACCATGGAGAAGGC-3'; reverse 5'-GGCATGGACTGTGGTC ATGA-3'). The final PCR process of each group is carried out in triplicate.

\subsection{Cytotoxicity analysis}

The cytotoxicity of $C-S-B$ nanoparticles, free siPlk1 and $C-S-B /$ siPlk1 nanoparticles $(\mathrm{N} / \mathrm{P}=5: 1)$ are evaluated by counting the levels of viable cells using a CCK-8 assay. HeLa cells are seeded in the 96-well plates at a density of $5-8 \times 10^{3}$ cells/well and grown overnight under standard culture condition. Cells are incubated with $C-S-B$ nanoparticles at $C-S-B$ polypeptide concentration ranging from 0 to $700 \mu \mathrm{g} / \mathrm{ml}$. Cell apoptosis caused by free siPlk1 and by $C-S-B /$ siPlk 1 nanoparticles is assayed by treating the cells with equivalent siRNA concentrations of $0,2,5,7,8$, $10 \mu \mathrm{g} / \mathrm{ml}$. Every concentration condition of each particle foemulation is operated in five wells parallelly. After incubation for $48 \mathrm{~h}$, the CCK-8 agent is added to determine the percentage of viable cells. Each well is added $100 \mu \mathrm{l}$ DMEM medium contained $10 \mu \mathrm{l}$ CCK- 8 and incubate at $37{ }^{\circ} \mathrm{C}$ for $1 \mathrm{~h}$. The UV absorbance of blank DMEM/CCK- 8 medium $\left(A_{\text {blank }}\right)$, cells without any treatment $\left(A_{\text {control }}\right)$ and with particle treatment $\left(A_{\text {smaple }}\right)$ at $425 \mathrm{~nm}$ are measured by a multi-well plate reader (BioTek). The cell viability is calculated by the formula as followed.

Cell Viability $(\%)=\left(A_{\text {sample }}-A_{\text {blank }}\right) /\left(A_{\text {control }}-A_{\text {blank }}\right) \times 100 \%$

A live/dead cell viability assay is carried out to further confirm the viability of cells which treated with $C-S-B$ nanorods, siPlk1 and $C-S-B$ / siPlk1. Typically, Calcein AM is used to stain viable cells and EthD-1 is used to stain nonviable cells. Cells are seeded in 6-well plates. Next, the cells are incubated for $48 \mathrm{~h}$ with Lipo/siPlk1 complexes, free siPlk1 and $C-S$ - $B /$ siPlk1 nanoparticles $(\mathrm{N} / \mathrm{P}=5)$. After staining with $2 \mu \mathrm{M}$ calcein $\mathrm{AM}$ and $4 \mu \mathrm{M}$ EthD-1 for $20 \mathrm{~min}$, cells are observed by fluorescence microscope (Leica) with green fluorescence taken to mean viable cells and red fluorescence taken to mean dead cells.

\subsection{Co-localization analysis of lysosomes and C-S-B nanorods in HeLa cells}

HeLa cells $\left(5 \times 10^{4}\right)$ are seeded in coverglass-bottom confocal dishes and cultured overnight under standard culture conditions. Next, cells are incubated for $12 \mathrm{~h}$ with Cy3 labeled $C-S-B$ nanorods at a concentration of $100 \mu \mathrm{g} / \mathrm{ml} C-S-B$. Then, $100 \mathrm{nM}$ Lysotracker Green is added followed by a further $15 \mathrm{~min}$ of incubation to stain the lysosomes. Cells are kept in phenol red free DMEM medium before being observed by CLSM. The co-localization ratio is calculated by the Nikon NIS software.

\subsection{Statistical analysis}

Statistical evaluations of the data are performed using the Student's $t$-test. All results have been expressed as the mean \pm standard deviation unless stated otherwise. ${ }^{*} p<0.05,{ }^{* *} p<0.01$.

\section{Results and discussion}

The $C-S-B$ polypeptide has been shown to co-assemble with a variety of polyanionic templates into rod-shaped nanoparticles including double stranded and single stranded DNA [22], long mRNA [23], synthetic polyanions such as PAA [24], as well as supramolecular polyanions [25]. In the absence of a polyanionic template the $C-S-B$ also can assemble into rod-shaped nanoparticles, but this requires higher protein concentrations than in the presence of long polyanionic templates.

We first investigate the optimum charge ratio $(\mathrm{N} / \mathrm{P})$ required to obtain fully siRNA saturated complexes of the $C-S-B$ nanorods with the siPlk1. The result of an electrophoretic mobility shift assay is shown in Fig. 1a. We find that for $\mathrm{N} / \mathrm{P}=5$ and higher ratio, mobility of the complexes no longer decreases. Therefore, at least initially, for further investigation of the complexes of the $C-S-B$ polypeptides with the siPlk1, we select a charge ratio of $\mathrm{N} / \mathrm{P}=5$. Enzymatic assay with RNAse $\mathrm{A}$ indicating that $C-S-B$ could effectively protect siPlk1 from degradation (Fig. S1). Electrophoretic mobilities of the nanorods with and without siRNA are determined using electrophoretic light scattering. Results are shown in Fig. $1 \mathrm{~b}$. The $C-S-B$ nanorods have a moderately positive $\zeta$-potential of $5.7 \pm 0.26 \mathrm{mV}$ in doubly-distilled water, probably reflecting the contribution of the positively charged building blocks $B$. In the presence of siRNA at $\mathrm{N} / \mathrm{P}=5$, only part of this positive charge is neutralized, leading to a somewhat lower $\zeta$-potential of $4.83 \pm 0.11 \mathrm{mV}$. In pH 7.4 PBS buffer, the $\zeta$-potential of the naked $C-S$ - $B$ nanorods attains a slightly negative value of $-2.94 \pm 0.18 \mathrm{mV}$. Most likely this is due to the shielding of the positive charges of the binding blocks $B$ by salt, such that the mobility is determined by the weakly net negative charge of the outer $C$ blocks. The addition of the siRNA decreases the $\zeta$-potential to $-6.80 \pm 0.87 \mathrm{mV}$.

TEM is used to characterize the morphology and dimensions of the $C-S-B$ nanorods and the complexes formed by the $C-S-B$ nanorods with siRNA at $\mathrm{N} / \mathrm{P}=5$. Results are shown in Fig. 2. Rod-shaped nanoparticles are observed both in the presence (Fig. 2a) and absence (Fig. 2b) of the siRNA. The lengths of all particles in Fig. $2 a$ and $b$ are determined and $a$ histogram is prepared for the lengths of the nanorods with and without siRNA (Fig. 2c). In the presence of the siRNA, the peak of the nanorod length distributions shifts to somewhat larger values. In the absence of siRNA, the location of the peak is at approximately $50 \mathrm{~nm}$, whereas in the presence of siRNA, it increases to approximately $70 \mathrm{~nm}$. DLS measurements are consistent with TEM results with the average size of $C$ $S-B$ and $C-S-B /$ siPlk1 of 45.2 and $68.3 \mathrm{~nm}$ (Fig. S2).

For long double stranded DNA, it was previously shown that each nanorod encapsulated exactly one long DNA molecule [22], but for long mRNA, it was found that most likely each nanorod contained a few mRNA molecules [23]. Since these long templates lead to long nanorods, the length distribution for these cases at high N/P is generally bidisperse with a peak for the long nucleic acid-encapsulating nanorods and a peak for the much shorter $C-S-B$ nanorods. For the very short siRNA templates, we instead find a length distribution with a single peak and a slight shift of this peak to larger nanorod lengths, in the presence of the siRNA. Hence, we cannot really tell that the self-assembly is templated by the siRNA. Instead it is probably more accurate in this case to state that the siRNA simply binds to the self-assembled $C-S-B$ nanorods and that the nanorod self-assembly is only mildly affected by the binding of the siRNA.

Then the uptake of the nanorods by HeLa cells after having been incubated with the nanorods for $4 \mathrm{~h}$ is observed by CLSM. C-S-B nanorods are fluorescent labeled with $\mathrm{Cy} 3$ by covalently conjugating with the amine groups on nanorods. Representative CSLM images are shown in Fig. 3a-c which clearly demonstrate that $C-S-B$ nanorods can be internalized by HeLa cells, indicating $C-S-B$ nanorods can be used as a delivery system into cells. To evaluate its siRNA delivery effect, siPlk1 has been chemically modified with Cy5 dye molecules. The CLSM images (Fig. 3d-f) show strong Cy5 fluorescent signals in HeLa cells after incubated with $C-S-B / \operatorname{siPlk1-Cy5}(\mathrm{N} / \mathrm{P}=5)$ for $4 \mathrm{~h}$, indicating $C-S-B$ nanorods can be used as a promising gene carrier. The cellular uptake of $C$ $S-B$ nanorods and $C-S-B /$ siPlk1-Cy5 (N/P = 5) is confirmed by flow cytometry (Fig. 3g-h) and the internalized fluorescence significantly differentiates them from the untreated cells. 
a)

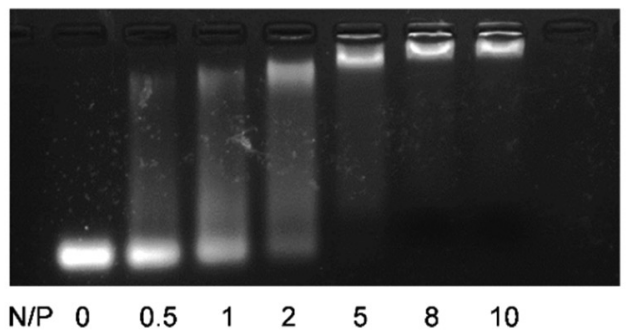

b)

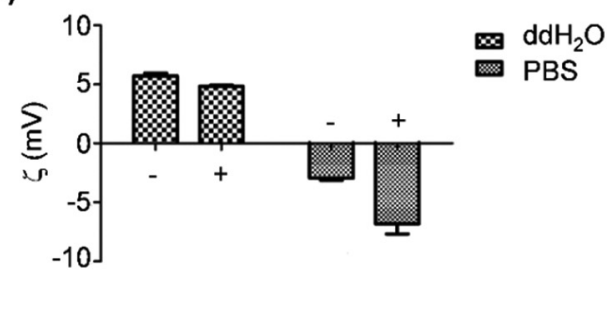

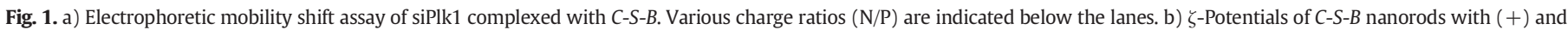
without ( - ) siPlk1 at $\mathrm{N} / \mathrm{P}=5$ for both $\mathrm{ddH}_{2} \mathrm{O}$ (hatched fill) and PBS (solid fill).
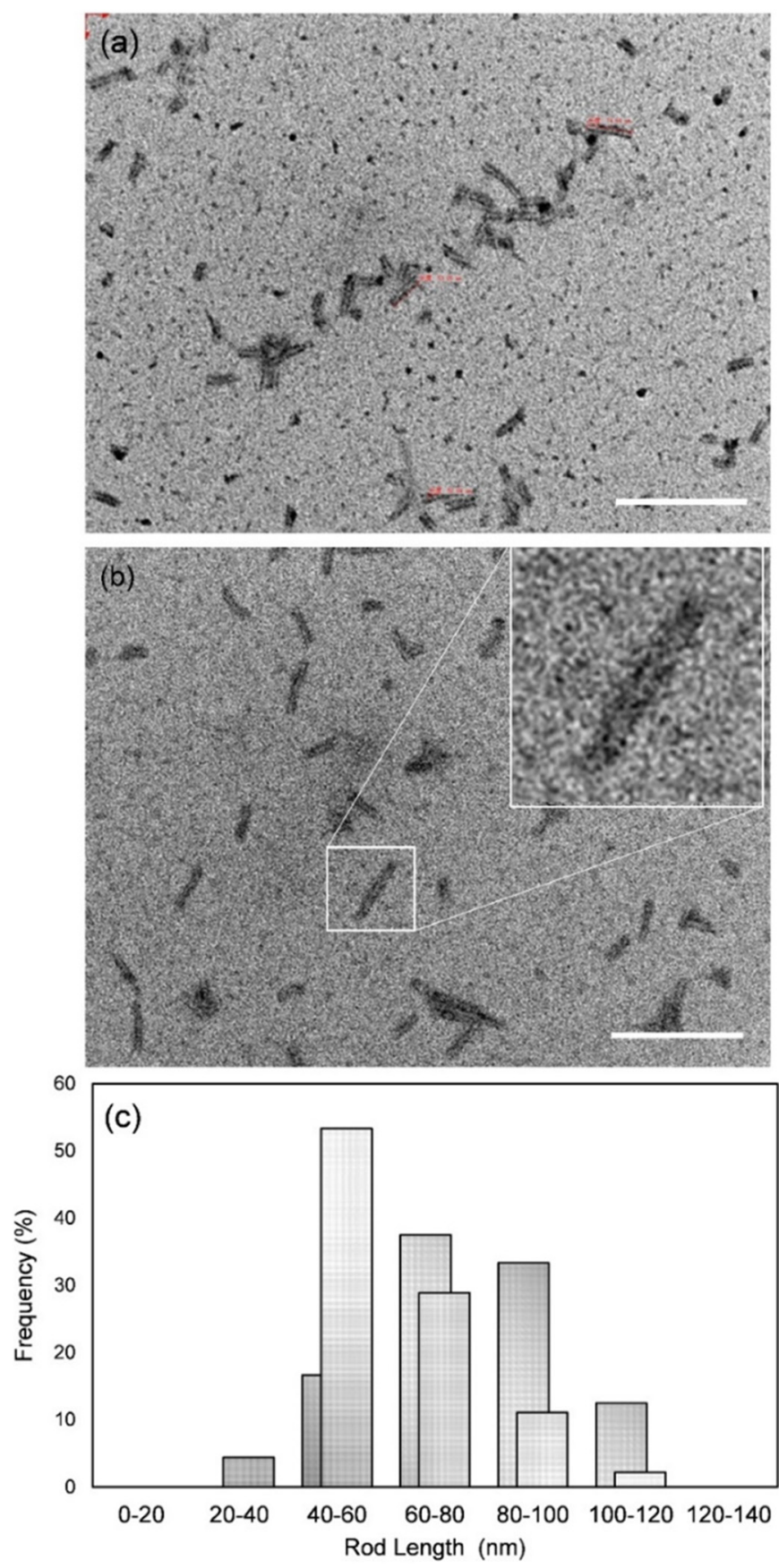

Fig. 2. TEM of self-assembled $C-S-B$ nanoparticles. a) $C-S-B$ alone b) $C-S-B$ with siRNA at N/ $\mathrm{P}=5$. Bar in a) and b) is $200 \mathrm{~nm}$. c) Length distributions for self-assembled nanorods without (light grey) and with siRNA (dark grey), based on SEM images of a) and b).
Next, we investigate the gene knockdown effect of siPlk1 after being delivered to HeLa cells using the nanorods, by quantifying the Plk1 mRNA through reverse transcription PCR. Results are shown in Fig. 4. As a positive control, a commercial siRNA lipid-based transfection agent is used, and (using the recommended transfection agent dosage provided by the supplier) it reduces the mRNA expression to $20.0 \%$. In contrast, negatively charged siRNA is rapidly degraded and does not easily pass cell membranes. Consequently, free siPlk1 is displayed displays no reduction of the Plk1 mRNA level. For $C-S-B / s i R N A$ nanorods at equivalent siPlk1 concentrations of 1,4 and $10 \mu \mathrm{g} / \mathrm{ml}$, the Plk1 mRNA expression levels of $102.7 \%, 75.5 \%$ and $47.7 \%$ are achieved, indicating that the $C-S-B /$ siRNA nanorods do reduce the gene expression in a dose-dependent manner, but clearly are not as effective as the commercial lipid-based control.

The biocompatibility of $C-S-B$ via the quantification of HeLa cell viability after incubating the cells for $24 \mathrm{~h}$ is evaluated. Cell viability is quantified using a CCK-8 assay and results are shown in Fig. 5. For the empty $C-S-B$ nanorods, no significant cytotoxicity is observed even at the highest concentration( $700 \mu \mathrm{g} / \mathrm{ml} \mathrm{C}$-S-B polypeptide, Fig. $5 \mathrm{a})$. Besides, the hemolysis ratio with an increasing concentration of nanorods is also measured. The hemolysis ratios of $C-S-B$ nanorods at 10, 20, 50 and $100 \mu \mathrm{g} / \mathrm{ml}$ are $1.8,2.63,3.29$ and 6.57\% (Fig. S3), indicating that $C$ $S-B$ nanorods have a good biocompatibility. A similar result is obtained for the bare siPlk1 (Fig. 5b), indicating it cannot effectively enter the cells which is consistent with the RT-PCR results. Thus, any decrease in cell viability that we observe for the $C-S-B /$ siPlk1 nanorods must therefore be due to the effects of the siPlk1 rather than the carrier. As a Plk1 inhibitor, various siPlk1 delivered nanoparticles have been widely investigated as gene cancer agents clinically [19]. Indeed, for the $C-S$ - $B /$ siPlk1 nanorods, we observe a significant dose-dependent decrease in cell viability. This strongly suggests that the siPlk1 delivered by the $C-S-B$ nanorods have depleted the level of Plk1 mRNA, inhibited cell proliferation, decreased cell viability and lead to cell-cycle arrest in-vitro $[19,26]$. The $C-S-B /$ siPlk1 induced cell apoptosis causes the cell viability to decrease down to $65.7 \%$ at an equivalent siplk1 concentration of $10 \mu \mathrm{g} / \mathrm{ml}$.

The cell viability results are further confirmed by direct visualization using a live-dead cell viability assay. Results are shown in Fig. 6. Red represents dead cells (cells are stained with EthD-1) and green suggests live cells (cells are stained by calcein AM). As expected, for the untreated (Fig. 6a) and bare siPlk1 treated groups (Fig. 6b), we only find live cells. For the positive control which siPlk1 is delivered with the commercial transfection agent Lipofectamin RNAiMAX, at an equivalent siPlk 1 concentration of $1 \mu \mathrm{g} / \mathrm{ml}$, we find mostly dead cells, and additionally, dead cells are detached from the culture dish, thus leading to less cells in the field of view as compared to other groups (Fig. 6c). Finally, for the $C-S-B /$ siPlk1 nanorods at an equivalent siPlk1 concentration of $10 \mu \mathrm{g} / \mathrm{ml}$, we find a mixture of live and dead cells (Fig. 6d), consistent with the CCK-8 cell viability assays. Furthermore, RT-PCR results have demonstrated that the expression of mPlk1 is decreased (Fig. 4) and caused partial cell apoptosis (Fig. 5c). To understand better why the $C$ - 
a)

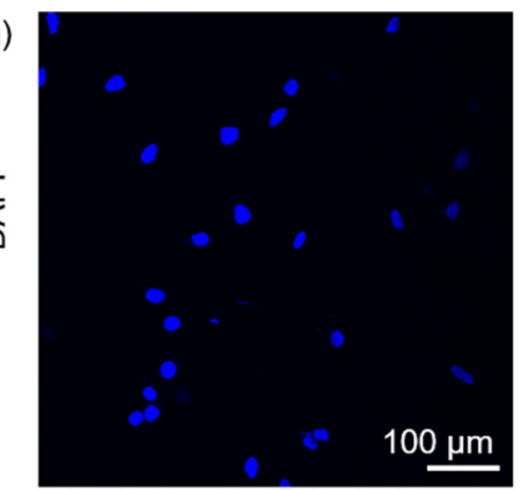

b)

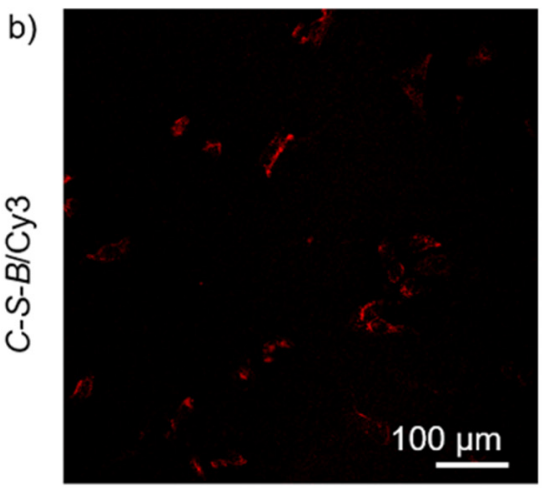

c)
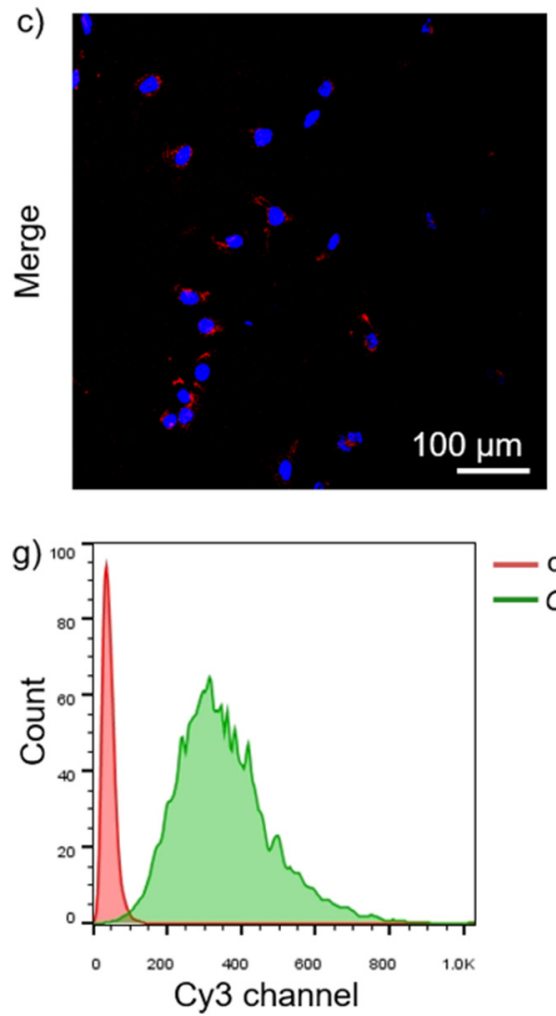

d)

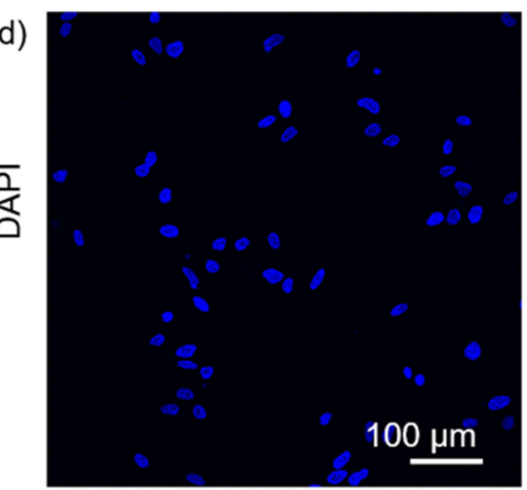

e)

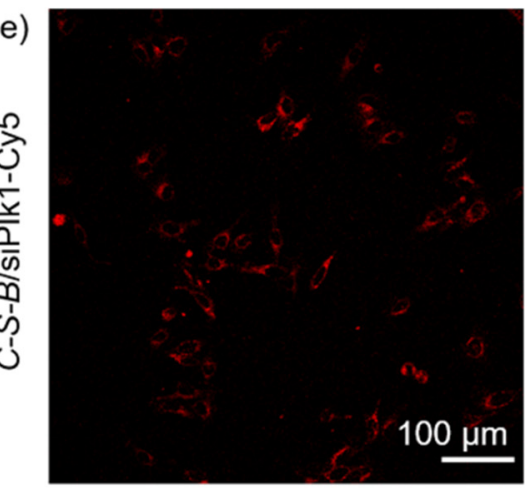

f)
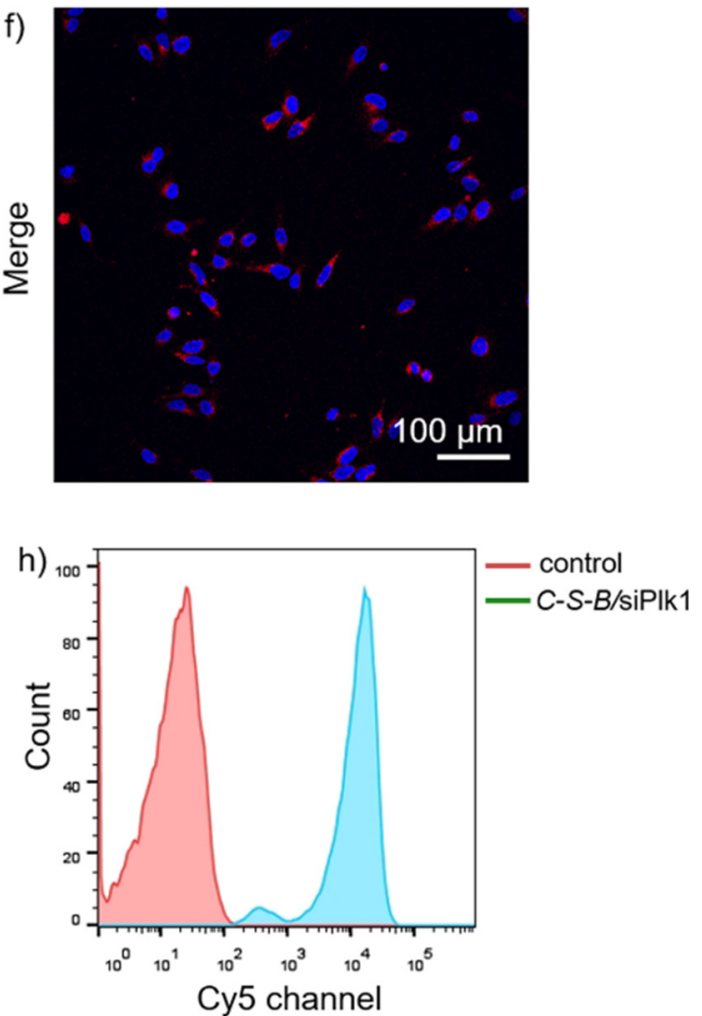

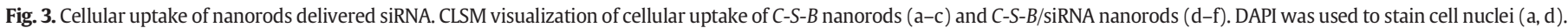

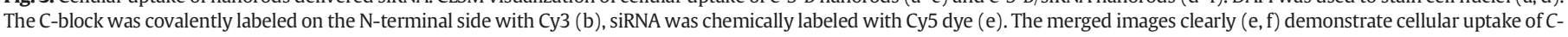
$S$ - $B$ and $C-S$-B/siRNA $(\mathrm{N} / \mathrm{P}=5)$ nanorods. Flow cytometry for HeLa cells having been incubated for $4 \mathrm{~h}$ with $C-S-B(\mathrm{~g})$ or $C-S-B /$ siRNA $(\mathrm{N} / \mathrm{P}=5)(\mathrm{h})$ nanorods.

$S-B /$ siPlk1 nanorods are so much less effective in inducing cell death than the positive control, we have tracked the cellular location of C-S$B$ nanorods using a CLSM co-localization assay. $C-S-B$ nanorods are fluorescent labeled with Cy5. Lysosomes are stained using lysosome tracker probe. As shown in Fig. 7, after incubation of the cells with the C-S-B nanorods for $12 \mathrm{~h}$, the overlay ratio of labeled $C-S-B$ and labeled lysosomes is $63.4 \%$, indicating that most of the $C-S-B$ nanorods are trapped in lysosomes. Thus, we tentatively identify insufficient endosomal escape as a major reason for the relatively low efficiency of gene knockdown effect by the $C-S-B / S i P l k 1$ nanorods in vitro. 
D. Li, X. Li, J. Bai et al.

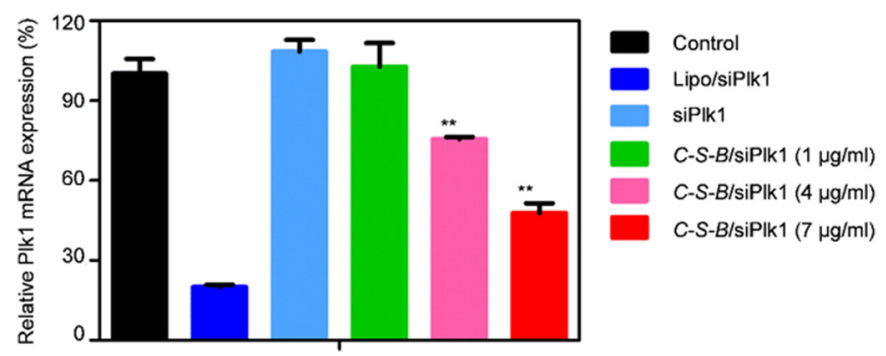

Fig. 4. Gene knockdown effect of $C-S-B /$ siPlk1 nanorods. Relative expression of Plk1 mRNA for: control sample (black); Lipo: positive control commercial transfection agent Lipofectamine/siPlk1 (blue) with equivalent siPlk1 concentration of $3 \mu \mathrm{g} / \mathrm{ml}$; bare siPlk1 at $7 \mu \mathrm{g} / \mathrm{ml}$ (light blue); increasing concentrations of $C-S-B /$ siPlk1 nanorods corresponding to siPlk1 concentrations of $1 \mu \mathrm{g} / \mathrm{ml}$ (green), $4 \mu \mathrm{g} / \mathrm{ml}$ (pink) and $7 \mu \mathrm{g} / \mathrm{ml}$ (red). ${ }^{* *} p<0.01$. (For interpretation of the references to color in this figure legend, the reader is referred to the web version of this article.)

a)

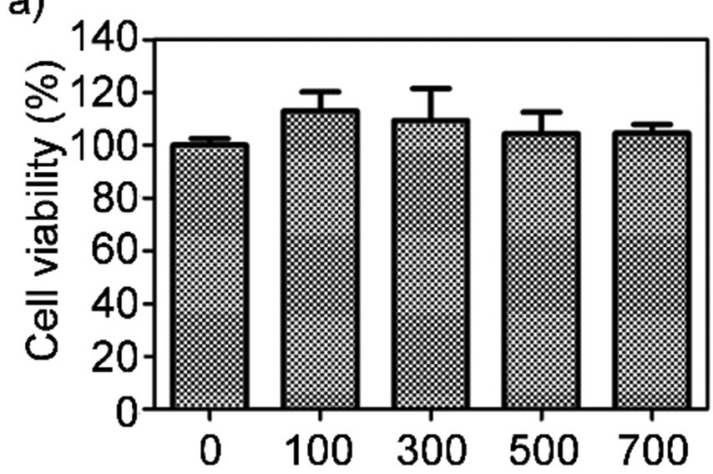

b)

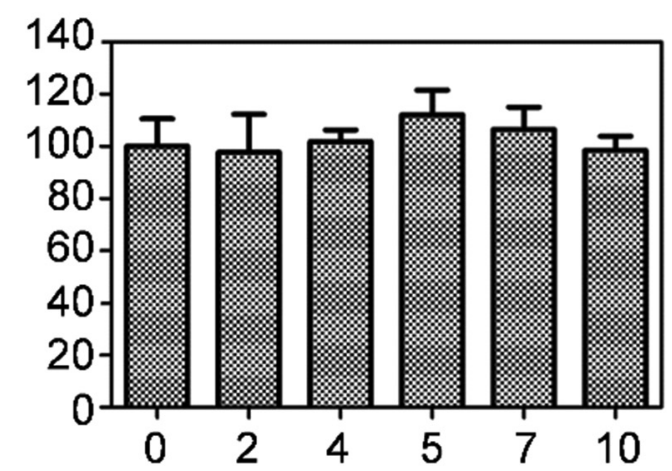

c)

siPlk1 concentration $(\mu \mathrm{g} / \mathrm{ml})$

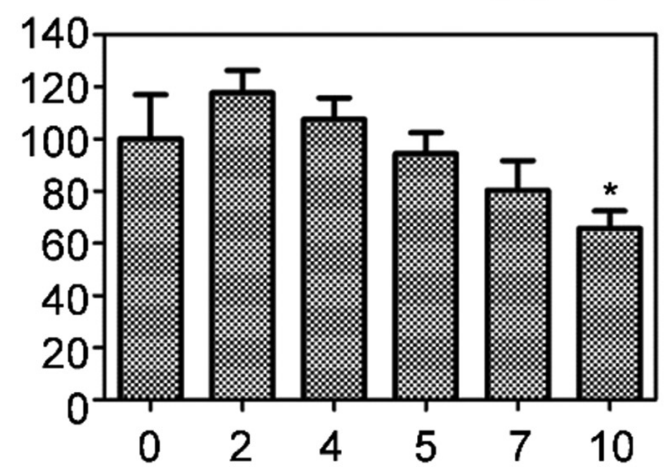

Equivalent siPlk1 concentration $(\mu \mathrm{g} / \mathrm{ml})$

Fig. 5. In vitro toxicity of $C-S-B /$ siRNA nanorods for HeLa cells by CCK-8 essay. a) Relative cell viability as a function of $C-S-B$ concentration for $C-S-B$ nanorods. b) Relative cell viability as a function of siPlk1 for bare siPlk1 siRNA. c) Relative cell viability as a function of equivalent concentration of siPlk1 for $C-S-B /$ siPlk1 nanorods. a)

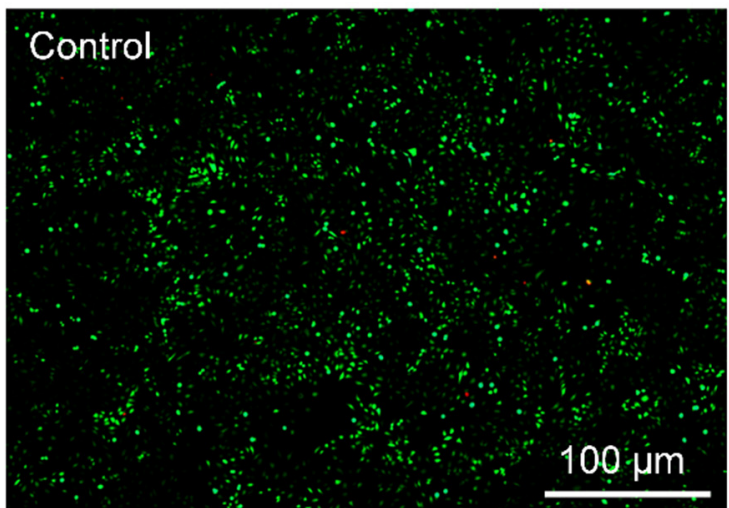

b)

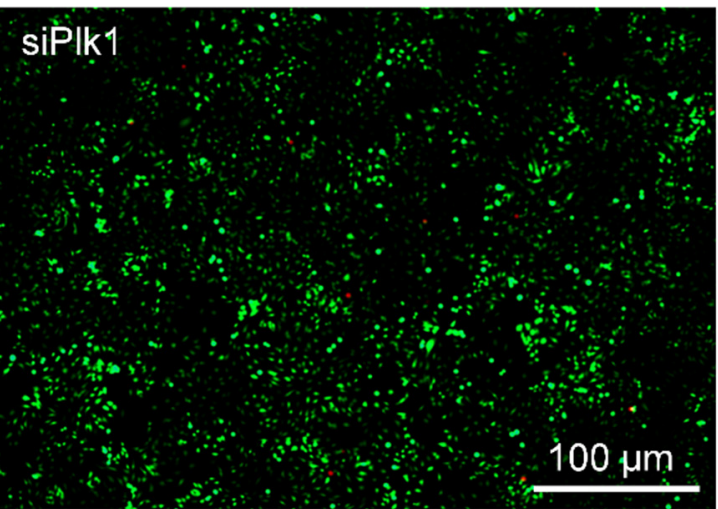

c)

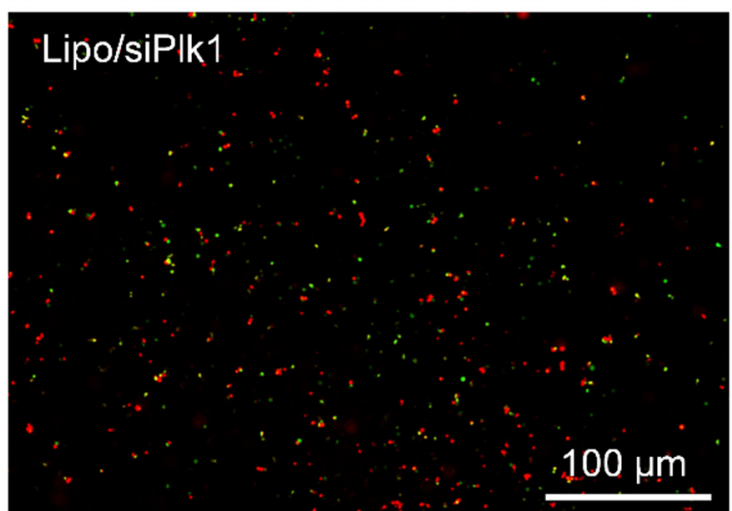

d)

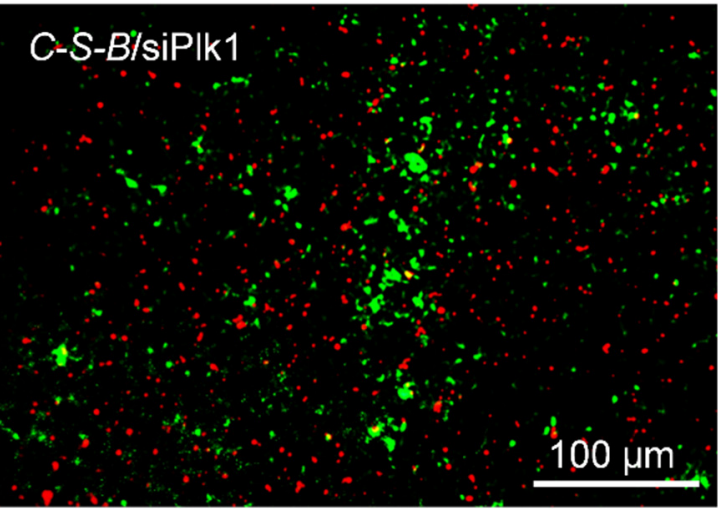

Fig. 6. Live/dead cell viability assay on HeLa cells incubated with $C-S-B /$ siPlk1 nanorods. Green are fluorescent labeled live cells, red are fluorescent labeled dead cells. a) Control; b) bare siPlk1; c) Commercial Lipofectamine/siPlk1 transfection agent positive control at equivalent siRNA concentration of $1 \mathrm{~g} / \mathrm{ml}$; d) $C-S-B /$ siPlk1 nanorods at N/P $=5$ and an equivalent siRNA concentration of $10 \mathrm{~g} / \mathrm{ml}$. (For interpretation of the references to color in this figure legend, the reader is referred to the web version of this article.) 

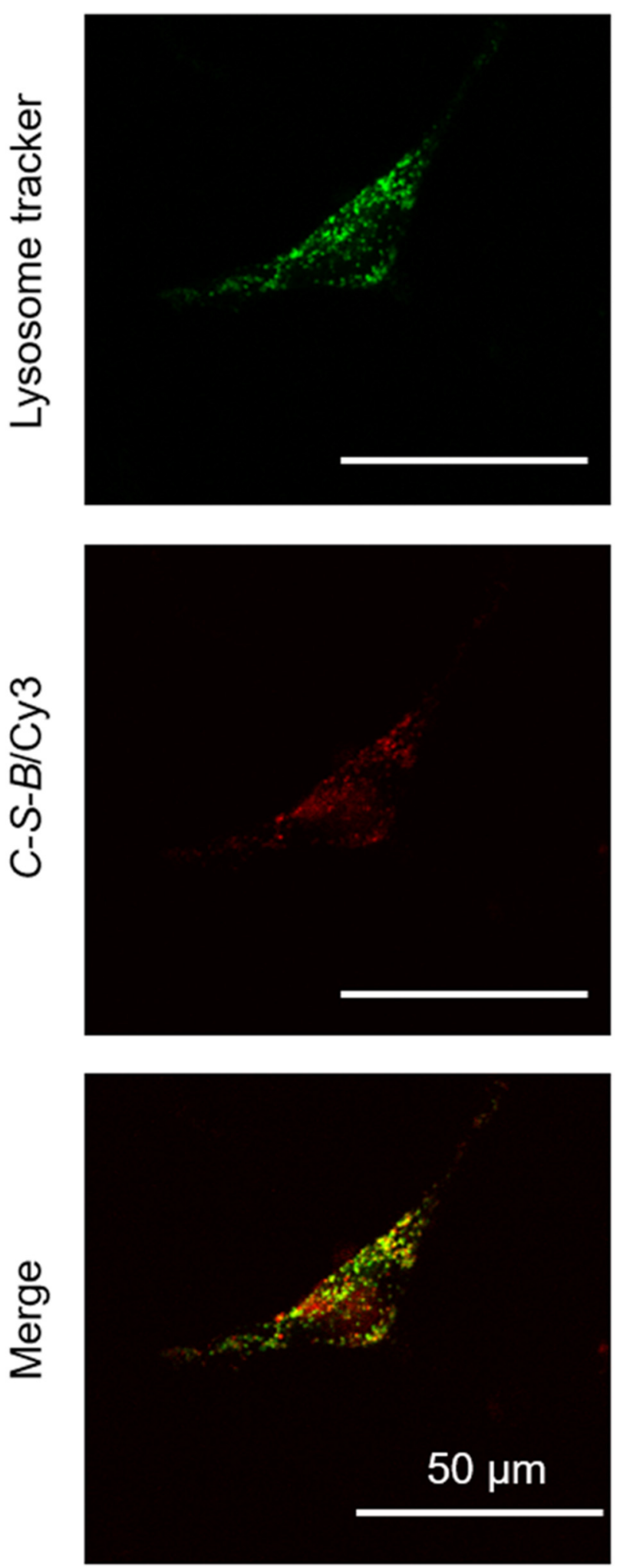

Fig. 7. The co-localization of the lysosomes and $C-S-B / C y 3$ after incubating for $12 \mathrm{~h}$. Green represents fluorescent labeled lysosomes and red represent fluorescent labeled $C-S-B$ nanorods. The overlay ratio is $62.4 \%$, suggesting most $C-S-B$ nanorods are trapped in lysosomes. (For interpretation of the references to color in this figure legend, the reader is referred to the web version of this article.)

\section{Concluding remarks}

As compared to well established and much investigated nanoparticles for nucleic acid delivery, there is still much to learn for the more novel class of self-assembling nanoparticles based on proteins and polypeptides with de-novo designed amino-acid sequences. Given that the nanorod-forming polypeptides have in the first place been developed as a simple polypeptide mimic of the templated assembly as seen in rod-shaped viruses such as TMV [22], it is encouraging that they also seem to be able to deliver siRNA into HeLa cells, leading to the knockdown effect of gene expression, albeit not yet very effectively. Nanoparticle uptake is known to sensitively depend on the nanoparticle shape and morphology, but almost all lipid and polymer nanoparticles currently under development have spherical morphologies. Therefore, it would be of interest to further develop the siRNA-containing polypeptide nanorods further, by adding modifications to the polypeptide design that could enhance the transfection efficiency.

We have identified poor escape of the nanorods from lysosomes as a key factor in the relatively low efficiency of gene knockdown induced by the nanoparticles, hence future modifications should at least initially focus on improving endosomal escape. This could be achieved by using known strategies such via membrane disrupting peptides or via the $\mathrm{pH}$ buffering or proton sponge effect $[27,28]$. The former could be achieved by including sequences for membrane disrupting peptides within the sequence of the $C-S-B$ polypeptides, the latter by incorporating a large number of histidine residues, which could be done in all three blocks making up the $C-S-B$ polypeptides. For the silk block, the histidines could replace the glutamines in the silk block. In earlier work, we have already shown that silk fibrils incorporating histidines are acid soluble $[29,30]$. This could imply that the siRNA nanorods would fall apart during acidification in lysosomes. It would be interesting to see whether this would aid or oppose the final efficiency of gene knockdown.

We wish to emphasize that we found the nanorods by themselves are completely non-toxic. In addition, protein-based polymers such elastin-like and silk-like polypeptides have been shown to be nonimmunogenic, or only very weakly immunogenic [22,31]. This is a key advantage of the nanorods composed of protein-based polymers. A next step is obviously to investigate pharmacokinetics and in-vivo delivery for these new particles. Circulation time will be a major consideration. This will be mainly governed by the solvent exposed outside $C$ block. Interestingly, a number of (non-immunogenic) hydrophilic random coil polypeptides have been designed and studied in detail with the specific purpose of prolonging circulation time of proteins fused to them [32-36]. If necessary, these would be interesting candidate sequences for future designs.

\section{Declaration of competing interest}

The authors declare no competing financial interest.

\section{Acknowledgments}

This work is supported by the National Key Research and Development Program of China (2018YFD0400305), National Natural Science Foundation of China (NSFC 31471577; 31772014) and the Beijing Nova Program (No. Z181100006218071).

\section{Appendix A. Supplementary data}

Supplementary data to this article can be found online at https://doi. org/10.1016/j.ijbiomac.2020.10.198.

\section{References}

[1] Y. Yang, D. Nie, Y. Liu, M. Yu, Y. Gan, Advances in particle shape engineering for improved drug delivery, Drug Discov. Today 24 (2) (2019) 575-583, https://doi.org/ 10.1016/j.drudis.2018.10.006.

[2] S. Barua, J.-W. Yoo, P. Kolhar, A. Wakankar, Y.R. Gokarn, S. Mitragotri, Particle shape enhances specificity of antibody-displaying nanoparticles, Proc. Natl. Acad. Sci. U. S. A. 110 (9) (2013) 3270, https://doi.org/10.1073/pnas.1216893110. 
[3] B.M. Haryadi, D. Hafner, I. Amin, R. Schubel, R. Jordan, G. Winter, J. Engert, Nonspherical nanoparticle shape stability is affected by complex manufacturing aspects: its implications for drug delivery and targeting, Adv. Healthc. Mater. 8 (18) (2019), 1900352, https://doi.org/10.1002/adhm.201900352.

[4] G. Sharma, D.T. Valenta, Y. Altman, S. Harvey, H. Xie, S. Mitragotri, J.W. Smith, Polymer particle shape independently influences binding and internalization by macrophages, J. Control. Release 147 (3) (2010) 408-412, https://doi.org/10.1016/j. jconrel.2010.07.116.

[5] R. Agarwal, V. Singh, P. Jurney, L. Shi, S.V. Sreenivasan, K. Roy, Mammalian cells preferentially internalize hydrogel nanodiscs over nanorods and use shape-specific uptake mechanisms, Proc. Natl. Acad. Sci. U. S. A. 110 (43) (2013), 17247, https://doi. org/10.1073/pnas.1305000110.

[6] X. Huang, X. Teng, D. Chen, F. Tang, J. He, The effect of the shape of mesoporous silica nanoparticles on cellular uptake and cell function, Biomaterials 31 (3) (2010) 438-448, https://doi.org/10.1016/j.biomaterials.2009.09.060.

[7] H. Yang, Z. Chen, L. Zhang, W.-Y. Yung, K.C.-F. Leung, H.Y.E. Chan, C.H.J. Choi, Mechanism for the cellular uptake of targeted goldnanorods of defined aspect ratios, Small 12 (37) (2016) 5178-5189, https://doi.org/10.1002/smll.201601483.

[8] E. Hinde, K. Thammasiraphop, H.T. Duong, J. Yeow, B. Karagoz, C. Boyer, J.J. Gooding, K. Gaus, Pair correlation microscopy reveals the role of nanoparticle shape in intracellular transport and site of drug release, Nat. Nanotechnol. 12 (1) (2017) 81-89, https://doi.org/10.1038/nnano.2016.160.

[9] P. Kolhar, A.C. Anselmo, V. Gupta, K. Pant, B. Prabhakarpandian, E. Ruoslahti, S. Mitragotri, Using shape effects to target antibody-coated nanoparticles to lung and brain endothelium, Proc. Natl. Acad. Sci. U. S. A. 110 (26) (2013), 10753, https://doi.org/10.1073/pnas.1308345110.

[10] R. Agarwal, P. Jurney, M. Raythatha, V. Singh, S.V. Sreenivasan, L. Shi, K. Roy, Effect of shape, size, and aspect ratio on nanoparticle penetration and distribution inside solid tissues using 3D spheroid models, Adv. Healthc. Mater. 4 (15) (2015) 2269-2280, https://doi.org/10.1002/adhm.201500441.

[11] M. Yu, J. Wang, Y. Yang, C. Zhu, Q. Su, S. Guo, J. Sun, Y. Gan, X. Shi, H. Gao, Rotationfacilitated rapid transport of nanorods in mucosal tissues, Nano Lett. 16 (11) (2016) 7176-7182, https://doi.org/10.1021/acs.nanolett.6b03515.

[12] J. Wang, Y. Yang, M. Yu, G. Hu, Y. Gan, H. Gao, X. Shi, Diffusion of rod-like nanoparticles in non-adhesive and adhesive porous polymeric gels, J. Mech. Phys. Solids 112 (2018) 431-457, https://doi.org/10.1016/j.jmps.2017.12.014.

[13] D. Li, J. Zhuang, H. He, S. Jiang, A. Banerjee, Y. Lu, W. Wu, S. Mitragotri, L. Gan, J. Qi, Influence of particle geometry on gastrointestinal transit and absorption following oral administration, ACS Appl. Mater. Interfaces 9 (49) (2017) 42492-42502, https://doi.org/10.1021/acsami.7b11821.

[14] S. Thakur, R.V. Saini, P. Singh, P. Raizada, V.K. Thakur, A.K. Saini, Nanoparticles as an emerging tool to alter the gene expression: preparation and conjugation methods, Materials Today Chemistry 17 (2020), 100295, https://doi.org/10.1016/j.mtchem. 2020.100295

[15] E. Wagner, Polymers for siRNA delivery: inspired by viruses to be targeted, dynamic, and precise, Acc. Chem. Res. 45 (7) (2012) 1005-1013, https://doi.org/10.1021/ ar2002232.

[16] R. Kanasty, J.R. Dorkin, A. Vegas, D. Anderson, Delivery materials for siRNA therapeutics, Nat. Mater. 12 (11) (2013) 967-977, https://doi.org/10.1038/nmat3765.

[17] H.J. Kim, A. Kim, K. Miyata, K. Kataoka, Recent progress in development of siRNA delivery vehicles for cancer therapy, Adv. Drug Deliv. Rev. 104 (2016) 61-77, https:// doi.org/10.1016/j.addr.2016.06.011.

[18] D. Adams, A. Gonzalez-Duarte, W.D. O’Riordan, C.-C. Yang, M. Ueda, A.V. Kristen, I. Tournev, H.H. Schmidt, T. Coelho, J.L. Berk, K.-P. Lin, G. Vita, S. Attarian, V. PlantéBordeneuve, M.M. Mezei, J.M. Campistol, J. Buades, T.H. Brannagan, B.J. Kim, J. Oh, Y. Parman, Y. Sekijima, P.N. Hawkins, S.D. Solomon, M. Polydefkis, P.J. Dyck, P.J. Gandhi, S. Goyal, J. Chen, A.L. Strahs, S.V. Nochur, M.T. Sweetser, P.P. Garg, A.K. Vaishnaw, J.A. Gollob, O.B. Suhr, Patisiran, an RNAi therapeutic, for hereditary transthyretin amyloidosis, N. Engl. J. Med. 379 (1) (2018) 11-21, https://doi.org/ 10.1056/NEJMoa1716153.

[19] P. Barata, A.K. Sood, D.S. Hong, RNA-targeted therapeutics in cancer clinical trials: current status and future directions, Cancer Treat. Rev. 50 (2016) 35-47, https:// doi.org/10.1016/j.ctrv.2016.08.004.
[20] C. Bao, B. Liu, B. Li, J. Chai, L. Zhang, L. Jiao, D. Li, Z. Yu, F. Ren, X. Shi, Y. Li, Enhanced transport of shape and rigidity-tuned $\alpha$-lactalbumin nanotubes across intestinal mucus and cellular barriers, Nano Lett. 20 (2) (2020) 1352-1361, https://doi.org/ 10.1021/acs.nanolett.9b04841.

[21] M. Caldorera-Moore, N. Guimard, L. Shi, K. Roy, Designer nanoparticles: incorporating size, shape and triggered release into nanoscale drug carriers, Expert Opin. Drug Deliv. 7 (4) (2010) 479-495, https://doi.org/10.1517/17425240903579971.

[22] A. Hernandez-Garcia, D.J. Kraft, A.F. Janssen, P.H. Bomans, N.A. Sommerdijk, D.M. Thies-Weesie, M.E. Favretto, R. Brock, F.A. de Wolf, M.W. Werten, P. van der Schoot, M.C. Stuart, R. de Vries, Design and self-assembly of simple coat proteins for artificial viruses, Nat. Nanotechnol. 9 (9) (2014) 698-702, https://doi.org/10. 1038/nnano.2014.169.

[23] S. Jekhmane, R. de Haas, O. Paulino da Silva Filho, A.H. van Asbeck, M.E. Favretto, A. Hernandez Garcia, R. Brock, R. de Vries, Virus-like particles of mRNA with artificial minimal coat proteins: particle formation, stability, and transfection efficiency, Nucl. Acid Ther. 27 (3) (2017) 159-167, https://doi.org/10.1089/nat.2016.0660.

[24] A. Hernandez-Garcia, M.A. Cohen Stuart, R. de Vries, Templated co-assembly into nanorods of polyanions and artificial virus capsid proteins, Soft Matter 14 (1) (2018) 132-139, https://doi.org/10.1039/c7sm02012k.

[25] A. Hernandez-Garcia, A.H. Velders, M.A.C. Stuart, R. de Vries, J.W.M. van Lent, J. Wang, Supramolecular virus-like nanorods by coassembly of a triblock polypeptide and reversible coordination polymers, Chem.-Eur. J. 23 (2) (2017) 239-243, https:// doi.org/10.1002/chem.201603968.

[26] Y. Degenhardt, T. Lampkin, Targeting polo-like kinase in cancer therapy, Clin. Cance Res. 16 (2) (2010) 384-389, https://doi.org/10.1158/1078-0432.CCR-09-1380.

[27] L. Carola, H. William, Membrane disrupting lytic peptides for cancer treatments, Curr. Pharm. Design 10 (19) (2004) 2299-2310, https://doi.org/10. 2174/1381612043383971.

[28] A.K. Varkouhi, M. Scholte, G. Storm, H.J. Haisma, Endosomal escape pathways for delivery of biologicals, J. Control. Release 151 (3) (2011) 220-228, https://doi.org/10. 1016/j.jconrel.2010.11.004.

[29] A. Hernandez-Garcia, M.W.T. Werten, M.C. Stuart, F.A. de Wolf, R. de Vries, Coating of single DNA molecules by genetically engineered protein diblock copolymers, Small 8 (22) (2012) 3491-3501, https://doi.org/10.1002/smll.201200939.

[30] C. Zhang, A. Hernandez-Garcia, K. Jiang, Z. Gong, D. Guttula, S.Y. Ng, P.P. Malar, J.A. van Kan, L. Dai, P.S. Doyle, R.d. Vries, J.R.C. van der Maarel, Amplified stretch of bottlebrush-coated DNA in nanofluidic channels, Nucleic Acids Res. 41 (20) (2013) e189, https://doi.org/10.1093/nar/gkt783.

[31] D.W. Urry, T.M. Parker, M.C. Reid, D.C. Gowda, Biocompatibility of the bioelastic materials, poly(GVGVP) and its $\gamma$-irradiation cross-linked matrix: summary of generic biological test results, J. Bioact. Compat. Polym. 6 (3) (1991) 263-282, https://doi. org/10.1177/088391159100600306.

[32] W.R. Strohl, Fusion proteins for half-life extension of biologics as a strategy to make biobetters, BioDrugs 29 (4) (2015) 215-239, https://doi.org/10.1007/s40259-0150133-6.

[33] W. Liu, M.R. Dreher, D.Y. Furgeson, K.V. Peixoto, H. Yuan, M.R. Zalutsky, A. Chilkoti, Tumor accumulation, degradation and pharmacokinetics of elastin-like polypeptides in nude mice, J. Control. Release 116 (2) (2006) 170-178, https://doi.org/10. 1016/j.jconrel.2006.06.026.

[34] M. Schlapschy, U. Binder, C. Börger, I. Theobald, K. Wachinger, S. Kisling, D. Haller, A Skerra, PASylation: a biological alternative to PEGylation for extending the plasma half-life of pharmaceutically active proteins, Protein Eng. Des. Sel. 26 (8) (2013) 489-501, https://doi.org/10.1093/protein/gzt023.

[35] V. Schellenberger, C.W. Wang, N.C. Geething, B.J. Spink, A. Campbell, W. To, M.D. Scholle, Y. Yin, Y. Yao, O. Bogin, J.L. Cleland, J. Silverman, W.P. Stemmer, A recombinant polypeptide extends the in vivo half-life of peptides and proteins in a tunable manner, Nat. Biotechnol. 27 (12) (2009) 1186-1190, https://doi.org/10.1038/nbt. 1588.

[36] S. Banskota, P. Yousefpour, N. Kirmani, X. Li, A. Chilkoti, Long circulating genetically encoded intrinsically disordered zwitterionic polypeptides for drug delivery, Biomaterials 192 (2019) 475-485, https://doi.org/10.1016/j.biomaterials.2018.11.012. 